\title{
Constituição e feminismo entre gênero, raça e direito: das possibilidades de uma hermenêutica constitucional antiessencialista e decolonial
}

\author{
Constitution and feminism between gender, race and law: the possibilities of an \\ anti-essentialist and decolonial constitutional hermeneutics \\ Constitución y femenismo entre género, raza y derecho: de las posibilidades de una \\ hermenéutica constitucional anti-esencialista y decolonial
}

Camilla de Magalhães Gomes

We do language. That may be the measure of our live.

(Toni Morrison)

guarda afasta-se então da porta da Lei, aberta como sempre, e o homem curva-se para olhar lá dentro.

(Franz Kafka)

\section{Resumo}

$\mathrm{Na}$ tentativa de utilizar gênero e raça como categorias de leitura e interpretação da Constituição brasileira, nesses seus trinta anos de existência, o presente artigo promove, em primeiro lugar, uma discussão sobre a linguagem jurídica, para assentá-la como performatividade, e, em segundo, apresenta o direito como parte da colonialidade. Com essas duas bases teóricas, a performatividade e a colonialidade, entende-se a Constituição como texto performativo que cria realidades e que, para que possa ser interpretada de modo feminista, antiessencialista e decolonial, precisa revelar e reinscrever essa sua herança colonial. A defesa de uma hermenêutica constitucional de gênero e raça, assim, passará por pensar o corpo como categoria jurídica, desnaturalizando as compreensões que temos a seu respeito e tomando-o em suas múltiplas formas e vivências, para permitir mais em nossas leituras sobre o humano no direito e no constitucionalismo.

Palavras-chave: Decolonialidade. Feminismo. Gênero. Hermenêutica constitucional. Raça.

\footnotetext{
Doutora em Direito, Estado e Constituição pela Universidade de Brasília. Professora do Centro Universitário de Brasília. E-mail: camillamaggo@gmail.com

Recebido em 25/5/2018 - Aprovado em 22/6/2018 http://dx.doi.org/10.5335/hdtv.18n.3.8593
} 


\section{Introdução}

Certamente, é possível falar dos trinta anos da Constituição da República Federativa do Brasil a partir de uma variedade de pontos de vista. De uma perspectiva histórica da constituinte, de um ponto de vista da filosofia política ou de uma abordagem mais dogmática, entre tantos exemplos. Escolho, contudo, realizar uma análise talvez bastante específica: levantar as possibilidades de uma hermenêutica constitucional que seja realizada (ou que tenha por critérios) nos marcos de gênero e raça. É um primeiro desenvolvimento, de um lado, fruto de meu trabalho de doutoramento e, de outro, como começo de um propósito de desenvolver aos poucos, talvez - teoria ou critérios para essa forma de fazer interpretação constitucional. Assim, o que apresento são alguns primeiros delineamentos com vistas a uma hermenêutica constitucional de gênero e raça.

Antes, vale pontuar que sustento ser o gênero

[...] uma categoria de análise capaz de desestabilizar o que é ser homem ou ser mulher apenas quando percebido não como uma categoria primária, secundarizando a raça, mas como categoria junto a ela produzida (MAGALHÃES GOMES, 2018, p. 69, grifo da autora).

Essa afirmativa será o mote para pensar o presente trabalho, o que significa que, talvez diferente de realizar uma hermenêutica constitucional feminista, proponho, como já referido, uma hermenêutica nos marcos de gênero e raça ou uma hermenêutica feminista antiessencialista e decolonial. ${ }^{1}$
Além disso, é importante destacar que identifico gênero e raça analisados na articulação de quatro categorias: corpo, sexo, gênero e raça, entendendo que os três últimos podem ser caracterizados como regimes, conjuntos, estruturas e sistemas e práticas de atribuição de linguagens aos corpos, e esses processos de atribuição de linguagem são processos de atribuição de humanidade. Atribuir sentidos aos corpos, em uma sociedade que se move em uma matriz de inteligibilidade cis-heteroconforme e colonial (MAGALHÃES GOMES, 2017a), é conferir a estes humanidade, em processos diferenciais e desiguais, sustentados pela dicotomia fundante da colonial/modernidade - humanos e não humanos (LUGONES, 2014) - preenchida, com destaque para o que discuto neste momento, pelas linguagens de gênero e raça.

Por essa razão, minha tentativa de realizar a construção de uma hermenêutica constitucional de gênero e raça passa por introduzir o corpo na teoria e por teorizar sobre o corpo e o direito para me permitir fazer de outro modo o humano entrar no jurídico. Quando se fala em direito, em Constituição, em teoria constitucional e teoria e filosofia jurídica, contudo, tradicionalmente, não se trabalha com o corpo. Mais do que isso, recusa-se o corpo. Quando falo em recusa, falo na recusa em teorizar sobre ou com o corpo. E falo justamente como um perigo: a recusa de teorizar sobre o corpo ou com o corpo é a operação de esconder que sua atividade trabalha, produz, fabrica e controla corpos. Talvez, por isso mesmo, a recusa como modo de permitir essa violência dos corpos, como modo de continuar sendo ins- 
tância de produção de vida e morte, na operação de uma necropolítica que decide quem pode viver (MBEMBE, 2003). Por isso, então, meu propósito de afirmar o corpo, afirmar as corporalidades contra o seu uso que decide quais corporalidades podem ter lugar, contra os essencialismos e as abstrações universalizantes que reduzem e violentam as tantas corporalidades em nome de padrões normativos e coloniais de gênero e raça.

Como, então, usar essa categoria? Como usar essa categoria - lida na relação corpo-sexo-gênero-raça - para pensar o humano do e no direito, para pensar e ler a Constituição como instrumento expansivo das multiplicidades (VIVEIROS DE CASTRO, 2015) e das pluriversalidades (MIGNOLO, 2000) de corpos e sujeitos, nos marcos de gênero e raça? Ocorre que o direito é parte dos processos de subjetivação, parte da constituição de uma linguagem na qual nascemos, uma linguagem em que somos inseridos independente de escolha ou decisão, parte desse processo de atribuição de linguagens aos corpos que é processo de atribuição de humanidade: somos formados na violência de uma linguagem que nunca escolhemos. Isso significa que mudar essa linguagem ou pensá-la de outro modo é urgente para produzir outras formas de subjetivação, formas menos violentas, formas menos limitadoras. Introduzir o corpo como categoria não é buscar uma emanação de natureza nem um argumento de real ou material para fundar a teoria. É mostrar como as múltiplas existências do corpo estão além da teoria e são esmagadas por uma teoria ou ideologia de controle e restrição que define a quem se confere humanidade.
A tentativa é a de mostrar como o corpo é tanto o lugar de recusa da teoria quanto o lugar de possibilidade de expansão. Apenas por isso, então, afasto-me de nomear o que busco de hermenêutica feminista. Sem dúvida, é junto a ela que pensarei, é também a partir de construções do feminismo que me movo, em especial do feminismo que tem o gênero como categoria de análise. Contudo, na tarefa de afirmar a impossibilidade de se falar de gênero sem trabalhá-lo ao lado da raça, penso em que caminhos seguir para fazer uma hermenêutica constitucional de gênero e raça.

Reflito que, ao pensar lado a lado teoria de gênero e direito, para tentar atender a esse propósito de pensar a interpretação da Constituição, considerando as categorias colocadas, a resposta passa por assumir um ponto em comum entre gênero e direito, ${ }^{2} \mathrm{e}$ esse ponto é sua característica performativa: o direito é um ato de fala primordialmente performativo, e o gênero é uma performatividade, um fazer, um agir (BUTLER, 2003). Partir dessas categorias me leva a teorias que também veem o próprio direito como performatividade, assim como teorias que o enxergam como parte ou produto da colonialidade. Assim, identifico o direito como uma performatividade, como uma declaração que, apesar de se pretender descritiva de realidades, $f a z$ algo no momento em que o enunciado é proferido. Ainda, considero o discurso hegemônico do direito inserido na produção da colonialidade, tomada como uma cadeia histórica de significados que organiza o pensamento de modo binário, hierarquizado e estruturado, no que aqui interessa, especialmente nas oposições nature- 
za/cultura, corpo/mente, não humano/humano. Essa forma de linguagem do direito ou essa forma de ver o direito como linguagem entre performatividade e colonialidade é o que segue.

\section{Direito é linguagem: o performativo do e no direito ${ }^{3}$}

Como pode ser realizada a tarefa de colocar os corpos e suas multiplicidades no direito? Como fazer caber esse encontro entre performatividade e decolonialidade que nos mostra que os corpos são muito mais que as linguagens que criamos para eles? Como usar esse campo de linguagem técnica, normativa, restritiva que é o direito? Como entrar nesta sempre aberta porta "da Lei" de que fala Kafka? O que (ou como) podemos significar esse "sempre aberta"? E como desafiar a autoridade que um "guarda" lhe confere? Estamos diante da lei. Vivemos a norma jurídica. Produzimos e somos produzidos por ela. Uma norma, contudo, que nos restringe, nos limita e, inclusive, nega humanidade a vários de nós. A pessoa é maior que a porta da Lei, precisa se abaixar para ver o que há lá dentro, mediante a autorização e o olhar atento de quem a guarda (DERRIDA, 1992).

Antes, quero comentar que talvez exista uma tensão entre a teoria da performatividade e a teoria decolonial, e falo não com pretensão de resolução, mas como tentativa de trabalhar com e nessa tensão. Quando faço a pergunta sobre se é possível ler o direito e a Constituição brasileira nos marcos de gênero e raça numa perspectiva expansiva do humano, uma leitura dos dois marcos teóricos referidos, se levados ao extremo, dir-me-ia que não, mostrando que a linguagem jurídica é restritiva. Em princípio, o que a teoria da performatividade e a decolonialidade mostram sobre esse campo é mesmo um retrato difícil de negar: um conjunto de epistemes enraizadas na matriz branca cis-heteroconforme (MAGALHÃES GOMES, 2017c, p. 16), cujo padrão é o ideal masculino cissexual branco. De outro modo, no entanto, é preciso defender a Constituição, defender a manutenção de um mínimo conquistado e fragilizado diante da contínua ameaça (mais do que disputa ou conflito) às conquistas constitucionais. Por difícil que pareça realizar uma busca de pretensões expansivas no direito - talvez fosse bem mais fácil fazer isso em filosofia, assumo essa frustração -, é preciso insistir e não abandonar o campo jurídico.

A tensão, contudo, está em como cada uma das teorias parece ver o normativo. Tomando o normativo em sentido amplo, extrapolando o normativo em sentido jurídico, seguindo uma narrativa foucaultiana, Butler (1997a) entende que não há fora da norma, não há fora da linguagem. Essa constitui o outro excluído da matriz - e que, portanto, está na matriz justamente como excluído. Assim, só há possibilidade de inscrever outros sentidos, subvertendo o normativo, dentro dele, e a autora trabalha isso tanto em um sentido geral, sobre o processo de subjetivação, quanto nos sentidos mais específicos, a respeito de gênero e de sexualidade. ${ }^{4}$ Já a decolonialidade desconfia do Estado - como Estado-Nação resultado da colonial/modernidade e, por consequência, de qualquer forma estatal de normatividade - e da sua 
possibilidade de ser outra coisa senão colonialidade. $^{5}$

Parece-me, então, que a tensão se atenua ou pode ser usada para trabalhar no campo jurídico em dois sentidos: enquanto os estudos decoloniais mostram onde e como opera o esquecimento da colonialidade 6 (MALDONADO-TORRES, 2008, p. 73), indicando como a norma - em especial aquelas instituições modernas que encarnam a norma: Estado, Nação e, por consequência, direito - é, desde o nascedouro, racializada; a performatividade entende que, não havendo fora da norma, é preciso trabalhar com suas linguagens para reescrevê-la e instaurar novas cadeias de significado. Assim, ainda que essa tensão não seja - nem será - resolvível, trabalhar nela pode ajudar a tentar "entrar no direito", usar o direito a favor dos fora da norma, dos "condenados" da norma, daqueles excluídos em razão do gênero e da raça, para produzir discursos que reinstaurem a cadeia de significados sobre o humano no direito.

É pensando, então, na urgência de se defender e ocupar o direito de outro modo que faço a leitura que segue, lembrando, como ressalta Rita Segato (2012), que o caminho é anfibio, e precisamos guardar sempre o cuidado de não colocarmos ambos os pés na institucionalidade que, como colonial que é, incorpora nossos pleitos, transformando-os, reduzindo-os e apagando os intervalos para que funcionem de novo ao modo binário moderno. Para isso, primeiro, farei uma pequena explicação sobre como leio o direito: o direito como performatividade. Essa forma de teorizar, acredito, permitirá pensar de outro modo como o humano entra no jurídico, para, no lugar de pretensões universalizantes so- bre o humano, poder realizar uma interpretação constitucional baseada nas categorias apresentadas.

Para abordar a ideia do direito como ato de fala performativo e dos significados dessa abordagem, vale, antes, realizar uma pequena introdução sobre o direito como linguagem, ou melhor, sobre o que significa, para este trabalho, a afirmação de que o direito é linguagem. Bourdieu afirmou, falando sobre a divisão do trabalho jurídico, que

[...] tudo leva a supor que a tendência para insistir na sintaxe do direito é mais própria dos teóricos e dos professores, enquanto que a atenção à pragmática é, pelo contrário, mas provável entre os juízes (BOURDIEU, 2011, p. 218).

$E$ as variações entre essas posições fazem parte do jogo de forças do campo. Nesta proposta, o que se faz talvez seja um caminho contrário ao que aponta Bourdieu: trabalhar o direito como ato de fala é, primeiro, colocar em perspectiva os usos da linguagem no direito e, segundo, ao inserir a perspectiva de que, como ato de fala, ele é em sua grande maioria performativo, significa analisar a linguagem do direito como um agir, como ação ou, como diz a teoria, como performatividade.

Com isso, quero dizer que lidar com o direito, tomando-o como linguagem do ponto de vista da teoria dos atos de fala, não é somente dizer que tipo de linguagem o constitui ou sobre como o fato de ser linguagem traz dificuldades de interpretação em razão da vagueza, da ambiguidade, etc. Assim, a proposta não é analisar o direito do ponto de vista da semiologia ou da semiótica de Saussure e Pierce, nem da filosofia 
analítica do segundo Wittgenstein, como já se tornou costume nas obras de teoria do direito, teoria da norma ou filosofia do direito. Esses debates já estão colocados e ainda dizem pouco sobre o que significa ser o direito uma linguagem, o que significa o uso da linguagem pelo direito, ou melhor, sobre que tipo de linguagem é o direito, quando o pensamos como criador e mantenedor de uma realidade como violência e sua linguagem como um modo de ação. ${ }^{7}$ Em resumo, não são suficientes para dizer sobre a dimensão performativa do direito como linguagem. Discutir o direito como performatividade é tomar o estudo da linguagem como a sua própria natureza e, ao mesmo tempo, identificar que é, também, um fazer.

Em segundo lugar, a análise do direito como linguagem é uma espécie de investigação sobre os usos (concretos) da linguagem, o que significa que, como aponta Rachel Nigro (2009), isso não se esgota em uma análise linguística,

[...] visto que não se separa a linguagem da realidade sobre a qual ela fala, como se se tratassem de duas realidades distintas. $\mathrm{O}$ uso da linguagem é uma forma de ação no real e não uma mera descrição da realidade.

É por isso que uma pragmática da linguagem jurídica passa por estudar não mais as proposições linguísticas (enunciados) como unidade de significação, mas

[...] o ato de fala, uma ação que se desenrola necessariamente no interior de um determinado contexto e cujo sentido não pode ser determinado de modo absoluto (NIGRO, 2009, p. 194-195).

Divirjo da autora apenas em seu entendimento de que o contexto é o ponto fundamental da construção de sentido, uma vez que leio a teoria dos atos de fala performativos com a revisitação desta que foi promovida por autoras como Judith Butler (1997b, 2003) e Shoshana Felman (2003). Falarei disso mais adiante. Por ora, é exatamente o ponto de usar o ato de fala como unidade de significação para a compreensão do que é o direito e a Constituição e do que é a linguagem jurídica aquilo de que me ocupo a seguir.

\section{Direito e Constituição como atos de fala performativos: a porta aberta da lei}

Muitos dos exemplos utilizados por John Austin (1975) na construção da sua teoria sobre os atos de fala performativos aqueles nos quais falar é fazer - foram retirados do mundo jurídico: casamentos, contratos, sentenças, condenações, vereditos, etc. A razão para tal não está em uma simples coincidência ou em uma escolha aleatória de exemplos, afinal, um ponto destacado pelo autor ao falar dos performativos é sua dimensão convencional, ritual. Tal é, inclusive, um dos critérios do conjunto para o funcionamento do performativo segundo o autor: a existência de um "[...] procedimento convencionalmente aceito que apresente um determinado efeito convencional e que inclua o proferimento de certas palavras, por certas pessoas, em certas circunstâncias", além de que " $[. .$.$] as pessoas e circunstâncias$ particulares, em cada caso, devem ser adequadas ao procedimento específico invocado" (AUSTIN, 1975, p. 31). Era-lhe tão óbvio que os atos jurídicos guardavam dimensão performativa que o surpreendia não terem os juristas percebido essa dimensão da fala, 
e atribui essa falha a uma obsessão desses em considerar que " $[. .$.$] os proferimentos legais$ e os proferimentos usados em, digamos, 'atos legais', tenham que ser de algum modo declarações verdadeiras ou falsas" (AUSTIN, 1975, p. 34).

Não deve ser nenhuma surpresa, assim, tomar o fenômeno jurídico diante de tal teoria. Warat apontava que as "normas jurídicas, por exemplo, contêm sempre uma instância performativa" (1995, p. 66). O que digo talvez vá um pouco além: o direito é performatividade; seus atos de produção, aplicação, interpretação - textos, discursos, decisões, teoria - são atos de linguagem performativos.

Uma leitura do direito como performatividade mostra que tal teoria serve para pensar o direito tanto como teoria quanto como lei. Não se trata, então, de falar de linguagem descritiva versus linguagem prescritiva, uma vez que ambas têm potencial ou são em si mesmo performativas. Afinal, falar o que o direito "é" também é em si agir, é construir um sentido para o direito, construir o direito. A filosofia e a teoria do direito têm suas dimensões performativas e, portanto, não configuram metalinguagens que falam de uma linguagem-objeto, o que significa que ambas cumprem "importantes funções políticas e ideológicas" (WARAT, 1995, p. 55).

O direito é uma instância de ficção e criação, um conjunto de textos que representam atos de fala performativos: as afirmações do texto jurídico são, em uma quantidade significativa de vezes, performativas, fazem algo no momento em que são proferidas. Ao contrário, então, do que se possa imaginar, o direito poucas vezes traz uma linguagem constatativa, de mera observação e descrição de uma realidade. A narrativa jurídica é performativa e "constrói sentidos e cria mundos" (NIGRO, 2009, p. 208-209), cria, no golpe de força de sua instauração, a realidade que diz apenas descrever (DERRIDA, 1991, p. 363). Sentenças, contratos, casamentos, constituições de empresas... o verbo jurídico performa a todo momento, cria realidade,

[...] o verbo realiza aç̃os ao invés de descrevê-las, e tais ações se constituem em atos jurídicos. Nesse entendimento, dizer é fazer, e o verbo enunciado assume o caráter performativo (MACIEL, 2008, p. 2-3).

Isso, porém, já parece bem óbvio: que o juiz, ao aplicar o texto legal, cria realidade, faz do sujeito culpado, dissolve uma relação matrimonial, desfaz uma pessoa jurídica. Declaratória, constitutiva, condenatória, mandamental, executiva: a decisão judicial (sentença), nas suas já clássicas modalidades, é um fazer (e nem falo em um "fazer justiça").

Mas não só o direito como atividade judicial assim se manifesta. Quando digo que o direito é um performativo, o que quero dizer é que o Direito é um performativo: os textos constitucionais, os legais e os da chamada "doutrina" ou "teoria" também são performativos. Prescrição e descrição não são tomadas como notas distintivas de duas instâncias do direito (a lei e a teoria), pelo contrário, performatização é o critério para analisar todo esse fenômeno jurídico-legal que cria uma realidade. E quando digo que o direito como performativo cria uma realidade, não estou falando apenas que ele cria a si mesmo, como autopoiese, como ato de 
criação da própria norma jurídica. Falo da criação de realidades, e uma interessa mais: a realidade do "humano" na matriz colonial do gênero, por meio do uso de categorias como povo, dignidade da pessoa humana e sujeito de direitos, por meio, portanto, da linguagem jurídico-constitucional.

Há que se tomar o cuidado, no entanto, quando se diz algo como "o direito cria realidades". O sentido do criar é o sentido do performar, e, desse modo, não quero dizer que com a promulgação de uma lei a realidade social é imediatamente transformada, como numa relação causa e efeito. Performar significa fazer por meio de palavras, e esse criar realidades tem então o sentido de que a linguagem jurídica não constata nenhum dado ou natureza, mas $f a z$ aquilo que declara. $\mathrm{O}$ direito como performatividade significa, portanto, que em poucos casos se encontra um a priori de caráter apenas ou puramente descrito ou constatado pelo discurso jurídico e tal se aplica ao direito de modo geral, mas, também, no que interessa ao trabalho de modo específico, a linguagem constitucional. A linguagem jurídica não descreve sujeitos, ela os cria ao dar significados diferentes a eles, ela cria a ficção do "sujeito de direitos". Não há um referente externo, prévio e defronte apenas descrito pela linguagem jurídica. Ademais, em sentido filosófico - e isso me interessa pois falo de direitos "humanos" e sobre o sentido do humano e de suas corporalidades que escapam aos sentidos estabelecidos -, o constatativo é sempre em alguma medida performativo (BUTLER, 1997b, p. 11). Isso tudo significa então que, não sendo uma descrição da realidade, a linguagem performativa funciona em sua citacionalidade, produz sentido e tem sentido por causa de sua capacidade de ser repetida. Nessa forma de ver, não há ato originário, o ato já é em si citacional, já é uma citação. Isso significa que há uma

[...] historicidade e uma história para o ato de fala: uma que é citacional e depende da iterabilidade e isso significa que apesar dele parecer funcional (proclamado aqui e agora, nesse espaço de tempo), ele só é operativo por referenciar outros contextos que já desapareceram (BUTLER, 2014, não paginado).

Isso apenas se ele reencenar uma cadeia histórica. Então, a própria compreensão que se tem do que seja um contexto também é em si uma performatividade, também é um conjunto de compreensões que se $f a-$ zem no momento do proferimento, isto é, os próprios contextos estão sempre sujeitos à revisão, são eles mesmos performativos e sempre sujeitos à citacionalidade e à iterabilidade.

Quando digo, então, que direito como texto teórico e como texto legal é um ato de fala performativo, estou dizendo, por consequência, que a promulgação de uma Constituição é um ato de fala performativo e que a própria Constituição também o é. Isso significa que: (i) os termos utilizados na Constituição instituem, muitas vezes, atos de fala performativos; (ii) como Constituição de um "Estado democrático de direito", sob o poder de um "povo", a carga performativa ou a força performativa - dessa espécie de ato de fala jurídico é ainda mais significativa: constrói-se um povo - ato performativo - ou reconhece-se um povo já existente ao descrevê-lo - ato constatativo? -, constrói-se um Estado democrático de direito - ato performativo - ou reconhece-se - ato constatati- 
vo? -, minha aposta é que ambas as questões são respondidas com a performatividade. $\mathrm{O}$ texto jurídico é ato, é "ação manifestada pelo verbo" (MACIEL, 2008, p. 4). ${ }^{8}$

O direito como uma ficção jurídica, normativa e estatalmente instaurada ganha significados ainda mais destacados quando se fala na construção da narrativa constitucional. Por um lado, porque se trata da "criação" de um "povo", daquelas pessoas que estão sujeitas ao direito, daqueles em nome de quem o direito diz que fala; por outro, porque essa "criação" atribui sentidos a algumas questões, como "sujeito", "pessoa humana" e "dignidade", que precisam ser relidas a partir do que são: não meras constatações de uma realidade ou de uma natureza, mas atos performativos, que estão sujeitos à interpretação, afinal, ser performativo já quer dizer ser interpretação: “a força performativa é sempre uma força interpretativa" (CHUEIRI, 2011, p. 804). ${ }^{9}$ Assim, é possível dizer que o componente performativo da Constituição não está apenas naqueles elementos de ritual, autoridade, convencionalidade, competência (MACIEL, 2008 , p. 2-3). A convencionalidade, sem dúvida, é um componente dos atos jurídicos, sejam eles legais ou judiciais. A Constituição como performativo está também e principalmente no fato de ela performar condições, estados, direitos, obrigações, relações entre aqueles a esse texto submetidos. É esse "ato performador inicial" meu objeto de análise neste texto, ou melhor, olhar esse ato como performativo é como se pode construir uma hermenêutica constitucional em marcos de gênero e raça. O promulgar, ${ }^{10}$ no preâmbulo da Constituição,
[...] tece uma rede de performatividade que perpassa o texto constitucional e sobremodaliza os verbos que, em nome da lei, executam atos jurídicos, tais como definir princípios, determinar a organização estatal, garantir direitos, estabelecer metas, atribuir poderes, reconhecer competências, ordenar, permitir e proibir condutas. Assim, a força ilocucionária do verbo promulgar gera um conjunto de enunciados performativos que transformam a totalidade do texto constitucional em um macroato de fala capaz de produzir efeitos legais no momento em que, atendidas todas as condições institucionais, no quadro semiótico do universo jurídico, o documento entra em vigor (MACIEL, 2008, p. 9).

Mas, se o performativo não tem um referente externo que descreve ou constata, se então a Constituição é um performativo, o que ela cria e mantém em sua força performativa? Que tipo de efeitos essa consideração pode produzir? É preciso analisar a promulgação de uma Constituição como ato que se autodeclara a voz do povo - por representação, vale lembrar -, baseado na ficção pressuposta de uma universalidade falante que desconhece particularidades, e lê-la como performativo é fazê-lo a favor do povo $e$ das particularidades dos sujeitos.

A partir dos referenciais teóricos utilizados, minha aposta é a de que, no que tange aos componentes humanos no texto constitucional - em especial povo e dignidade da pessoa humana e os direitos fundamentais correspondentes -, o ato de fala constitucional é uma cadeia histórica de linguagem que forma performativos perlocucionários, ou seja, entre o ato de proferir a fala e o efeito de criação há um intervalo de tempo e mesmo de espaço (AUSTIN, 1975; BUTLER, 2003; GOULD, 1995). Isso porque o ato de nomear 
e definir identidades não produz seus efeitos no mesmo momento em que é proferido. A constituição dos "sujeitos de direitos" e o modo como esses se identificam - e os termos mediante os quais se identificam - não se performam no momento em que o parágrafo único do artigo primeiro constitui um povo do qual todo o poder emana, poder esse fundado na dignidade da pessoa humana, ou a partir do momento em que se declaram "homens e mulheres iguais em direitos e obrigações", em seu artigo $5^{\circ}$.

Para que esse povo se constitua como tal, para que esses homens e mulheres sejam "produzidos" como seres dignos como efeito de uma voz constitucional, para que o reconhecimento de humanidade se produza com o menor conteúdo possível de exclusão, para que esse efeito se produza ou, em resumo, para que esse performativo funcione, há um tempo. Esses atos, assim, podem não produzir o efeito que nomeiam, e aqueles "destinatários" podem recusar as formas mediante as quais são constituídos e/ou interpelados. É nessa performatividade produtiva dos efeitos de uma dignidade como processo que é possível falar do ato de fala constitucional como performatividade perlocucionária. E é no espaço-tempo entre o proferimento e a produção dos efeitos, ouvidos os corpos falantes da linguagem ordinária, que será possível o vislumbre de reinscrever o que significa humano no direito, lendo e interpretando o texto constitucional nas articulações entre corpo, sexo, gênero e raça.
De uma hermenêutica constitucional feminista a uma hermenêutica feminista antiessencialista e decolonial nos marcos de gênero e raça

As considerações apresentadas até o momento exigem, então, o abandono de pretensões ou formulações essencialistas, para realizar uma hermenêutica constitucional feminista, pois, segundo o que ensina Angela Harris (1990), a teoria legal feminista não pode nem tomar por base um eu que conhece apenas particularidades, nem sustentar-se em um nós que desconhece completamente essas particularidades. A autora critica as formulações do campo fundadas em um essencialismo de gênero, uma vez que,

[...] na tentativa de se extrair um ser feminino essencial e falar da diversidade da experiência das mulheres, as experiências das mulheres percebidas como 'diferentes' são ignoradas ou tratadas como variações a norma (branca) (1990, p. 614).

O nós, o povo, preencheu por muito tempo e em uma extensa medida a teoria jurídica e, por consequência, a teoria legal feminista. Assim, a autora propõe que, “[...] para energizar a teoria jurídica, precisamos subvertê-la com narrativas e histórias, relatos sobre o particular, o diferente e o até então silenciado" (1990, p. 615).

Em razão disso, ao falar de feminismo, ao falar de gênero, proponho tratar referida categoria como uma das linguagens que atribuem sentido ao humano, uma das linguagens que atribuem humanidade aos corpos. Isso porque ela não existe e não trabalha sozinha, não se constrói sozinha e não realiza sozinha os processos de subjetivação dos corpos. Seguindo as lições do feminismo 
negro ${ }^{11}$ e ou do feminismo decolonial, ${ }^{12}$ sustento que uma hermenêutica constitucional feminista que se pretenda antiessencialista ${ }^{13}$ deve partir da consideração de que o gênero é racializado, e a raça é generificada.

Considerando que a linguagem jurídica é performativa e que ela é linguagem sobre corpos, linguagem produzida por corpos e é em si mesma, como performatividade, um ato corporal, sustento que, ao falar de humano, ao realizar hermenêutica constitucional sobre direitos fundamentais nos marcos de gênero e raça, as categorias articuladas de corpo, raça, sexo e gênero devem fornecer o substrato para a análise dos institutos jurídicos, e não o contrário: no lugar de usar o direito para pensar como trabalhar com raça e gênero, por exemplo, são os saberes sobre essas quatro categorias articuladas que devem fornecer o material para trabalhar o texto constitucional, em especial, os saberes produzidos por aqueles que vivem e produzem essa linguagem, que vivenciam, em seus corpos e em suas vidas, os modos de produção, estabelecimento e subversão dessas linguagens e suas normas. Escolher o gênero para questionar o sentido do humano, assim, é um ponto de partida relevante, uma vez que este, como forma de diferenciação binária de sujeitos imposta com a colonialidade (LUGONES, 2014), acaba por ocupar uma posição privilegiada de categoria de análise, porque é "dado como natural", como se "homens e mulheres" fossem essas unidades mínimas do humano. Trata-se da operação performativa realizada na Constituição.

Precisamente, é possível e necessário problematizar esse uso dos termos como dados de natureza. Estes são os desafios, e também necessidades urgentes, propostos pela decolonialidade: mudar o campo, mudar a epistemologia, performar desobediências epistêmicas (MIGNOLO, 2000). A questão não é apenas criticar o direito e como ele opera na prática em termos de gênero, mas, antes, avaliar o que ele toma como fixo, estável, dado, natural; o que ele toma e o que ele ajuda a tornar; o que, em sua dimensão discursiva, contribui para construir como norma (em sentido geral) a binariedade dos gêneros como sentido do humano.

Mas, como se pretende alterar o campo, o modo como se pensa sexo e gênero, se continuamos usando os mesmos referenciais teóricos? Se continuamos usando os mesmos "cânones", como se já houvéssemos descoberto a verdade sobre o feminismo, sobre o gênero e sobre o humano? Se continuamos produzindo discursos a partir desse mesmo lugar, em que a existência de homens e mulheres é um dado natural não questionável, em que sexo e gênero são colocados como conceitos rigidamente opostos, como se reproduzindo a oposição binária natureza/ cultura? Se analisamos o gênero como uma linguagem sobre corpos dissociada da linguagem de raça, como se fosse possível apenas somar os efeitos dessas linguagens sobre os corpos?

No modelo moderno do humano, ${ }^{14}$ naturalizado e essencializado, as particularidades não cabem. Nesse modelo, baseado na dicotomia corpo-mente, o primeiro é tomado como dado da natureza, apropriável pelos atributos do segundo (MALDONADO-TORRES, 2007). Contudo, a teoria decolonial, o feminismo, o movimento negro, os 
movimentos LGBTTQIA ${ }^{15}$ e todo o conhecimento produzido por aqueles que são $o \mathrm{ou}$ tro feito apenas corpo sem razão mostraram que essa razão, esse sujeito e essa mente descorporificada são a reprodução de um padrão hegemônico comumente identificado com o homem branco, cissexual, heteroconforme, classe média e fundado numa relação de dominação: razão que domina o corpo, cultura que domina a natureza, humanos que dominam não humanos, em relações de corporeidades racializadas e generificadas. Nesse sentido, diferente do que se pensa, o corpo não é objeto a-histórico, matéria pura a que a mente confere sentido. Ele é uma história, tem histórias, ganha seus significados dentro da história (FAUSTO-STERLING, 2012, p. 79). Ele é materialidade, mas, ao mesmo tempo, ganha materialidade por meio de discursos que reconhecem ou dão significado para alguns ao mesmo tempo em que negam significados - e humanidade, por consequência - a outros, excluídos; o que não significa que esses outros não existam, mas existem de modo precário, vulnerável, não dito, na margem, em um limite de negativa de humanidade constante.

$\mathrm{Na}$ articulação das categorias referidas, meu argumento é o de que, ao falar de humano e ao falar de humano no direito, para realizar hermenêutica constitucional, o fundamento deve ser o de que o que hoje se entende ou se usa como sexo/gênero foi construído no performativo da colonialidade, tendo a raça e o racismo como informadores dessa construção, ou seja, raça, sexo e gênero não surgem como conceitos separados, mas são forjados numa mesma matriz, que tem como estrutura binária central aquela de humanos/não humanos (LUGONES, 2014). Do colonialismo à colonialidade, a raça funciona como modo de desumanização do "não europeu" ou do "não branco" e atribui a este o lugar da natureza e do corpo - desprovidos de cultura e desprovidos de razão -, e a dimensão generificada do humano também lhe é negada e se atribui a estes apenas o sexo. ${ }^{16}$ As noções de gênero estão, desse modo, informadas por uma distinção racial, mas, mais do que isso, o que se entende por sexo e gênero é cunhado nessa mesma cadeia histórica de significados que tem a raça como informador, ou seja, são formados no performativo da colonialidade. Teorias, conceitos e práticas sobre sexo e gênero são produzidas informadas pela raça e pelo racismo e, quando não levam em conta esse componente, correm o risco, já diversas vezes denunciado, de reproduzir o humano universal das próprias teorias que criticam, deslocando-o apenas do "homem universal" para a "mulher universal" - uma mulher cissexual e branca -, e, com isso, continuam a essencializar sujeitos e experiências.

Se, então, a colonialidade usa a raça $e$ o sistema sexo/gênero em seu processo de desumanização e se, como pontuei no início e a seguir desenvolvo, o direito também é produzido no marco da colonialidade, para que essa cadeia histórica possa ser desautorizada de sentidos nos quais é produzido o performativo jurídico, é preciso que essa hermenêutica feminista tenha por categorias tanto o gênero quanto a raça, sendo feita, portanto, de modo antiessencialista e decolonial. Para isso, antes é preciso desfazer o texto jurídico-constitucional, para pensar o que ele recalca, o que ele recusa. 
Performatividade e decolonialidade para pensar o humano no direito

Por que usar a teoria da performatividade para o direito? A performatividade não só mostra a "normatividade de alguns tipos de alegações descritivas", mas também "oferece um caminho para pensar como algo novo pode vir da linguagem" (ATHANASIOU; BUTLER, 2013, p. 120). Olhar assim a linguagem jurídica traz a possibilidade de dizer diferente, a possibilidade de reinstaurar o performativo e instaurar novos direitos ou novas interpretações para velhas estruturas jurídicas, sem descartá-las, abandoná-las ou destruí-las. O performativo não é um ato único, ele ganha significado na reiteração, na repetição, na convenção. O performativo da colonialidade ganha significado por meio de sua reprodução em formas de poder e saber, e o direito é uma delas. Repetindo teorias que guardam herança na colonialidade, que recusam o corpo usando a teoria moderna autocentrada e autônoma do sujeito, reforça-se a negativa de que os corpos são sujeitos a linguagens que distribuem de modo diferencial a humanidade. Se e quando os conceitos jurídicos sobre o humano são encarados como atos de fala performativos, pode-se pensar em como fazer de outro modo.

E, repito, o direito é uma instância de ficção, ${ }^{17}$ é uma instância de criação e conjunto de textos que representam atos de fala performativos: as afirmações do texto jurídico são, em uma quantidade significativa de vezes, performativas, fazem algo no momento em que são proferidas, possuem capacidade de criar realidades. Essa ficção juridicamente instaurada também se faz presente quando se fala daquelas pessoas que estão sujeitas ao direito, em especial, daqueles que compõem o "povo", em nome de quem o direito diz falar, e os sujeitos dos direitos estabelecidos por e para esse povo. Essas considerações são ainda mais relevantes quando se fala de gênero e raça, de como se constitui o discurso do ato de fala constitucional nesse tema e quais são as possibilidades de sua compreensão.

Afinal, nesse processo de criação performado pelo direito de dar-se a si mesmo uma "Constituição", as possibilidades dos sujeitos ou os sujeitos possíveis são criados. E, se uma leitura do direito e da Constituição for feita de modo a pensá-los apenas como descritivos ou atos de fala constatativos, seria forçoso, então, dizer que a ordem jurídica brasileira reconhece apenas "homens e mulheres" assim definidos a partir do sexo, como uma mera constatação de uma circunstância naturalmente dada. No entanto, é importante pensar que a Constituição brasileira de $1988^{18}$ "cria" um povo também na perspectiva cis-heteroconforme do gênero, do sexo e do desejo, e isso significa que reler a Constituição - a partir da teoria dos atos de fala e das teorias do gênero e da decolonialidade - é um passo teórico e filosófico necessário para, em primeiro lugar, compreender o que é o caráter performativo do direito e, em segundo, realizar uma hermenêutica constitucional antiessencialista, buscando os caminhos para a garantia da dignidade e da cidadania desse "povo" para além da reprodução de uma matriz branco e cis-heteroconforme excludente, que se baseia nas identidades fixas masculino/feminino e que, assim, cria - para dentro do 
direito - e reforça aquilo que alega apenas constatar: a ficção de que somos um povo composto de homens e mulheres, como se tais fossem circunstâncias naturais e não produções discursivas da performatividade de corpos e discursos.

Entre povo e pessoa humana, entre universalidade e particularidades, há muito mais do que o sujeito de direitos é capaz de comportar. É esse o motivo de importar analisar o direito junto ao gênero, ou repensar o direito a partir do gênero, para colocar em perspectiva o caráter temporal, temporário, histórico e situado do texto jurídico. Se o gênero é uma categoria útil de análise histórica (SCOTT, 1986), também é uma categoria útil de análise jurídica. A violência do direito, a força de lei, no ato da assinatura da Constituição, diz definir o "povo", mas ela faz mais do que definir: ela faz o que diz, cria e constata a criação, ao mesmo tempo. Ao declarar que representa o povo, cria o povo, em um desenho que pode aparecer sob diferentes prismas e que, no entanto, interessa pela forma com que esse ato toma o gênero e a linguagem colonial como partes desse conceito/criação. A violência do direito, ao mesmo tempo em que declara algo, performa aquilo que declara, e o principal momento dessa performatividade é a assinatura do documento constitucional de um país.

Todavia, a luta pelo sentido jurídico não termina com a promulgação, como afirma Villegas (2014). A luta pelo sentido do direito nos processos de sua aplicação (e eu acrescentaria nos processos de sua compreensão, desde os campos da sua filosofia) é "tão ou mais intensa que a luta que teve lugar quando, no parlamento, se discutira o projeto que deu lugar a lei" (VILLEGAS, 2014, p. 15). É esse intervalo entre força e efeito, entre enunciação (ilocucionária) e produção (perlocucionária) de efeitos que pode permitir repensar essa pessoa humana como fundamento da República e como critério de interpretação de direitos fundamentais, e por isso a preocupação de construir linguagem - teórica e filosófica - para o direito a partir dos marcos teóricos apontados neste texto.

Nesse ponto, então, o trabalho se insere na direção contrária dessa instauração violenta ou redutora ou dessa ficção comentada, para reconhecer como e onde a violência da linguagem da colonialidade se manifesta e como e onde é possível promover um movimento de ruptura, de resistência e contraviolência no campo da filosofia do direito e da hermenêutica de direitos fundamentais. Ao reconhecer o caráter performativo do direito e assim sua força, é possível pensar em como usar essa força para promover processos de ruptura. Afinal, se a eficácia simbólica do direito está em dar nomes para criar realidades, ${ }^{19}$ é preciso refletir também sobre como esses nomes podem fazer caber a realidade vivida.

Enquanto, contudo, as teorias da performatividade, para o direito e para o gênero, fornecem o substrato teórico para caminhar na análise da relação gênero e direito para formar um pensamento para o humano no jurídico, elas não são, de modo algum, suficientes. Falo daqui da colônia, falo de um contexto latino-americano e brasileiro. De produções e performatividades de direito e de gênero nesse contexto histórico em que a raça e o racismo estão no centro de nossas 
produções de poder, saber, de ser e de gênero. Não só o gênero é esse ponto mínimo de definição do humano, mas no contexto colonial, a raça é também responsável por como pensamos o humano e mesmo por como pensamos o gênero. Assim, usar o gênero como categoria de análise talvez seja o ponto de partida para dar outro significado ao povo e à dignidade da pessoa humana como fundamento da República brasileira, e nisso estou com muitas autoras que identificam a importância do feminismo para pensar a hermenêutica constitucional.

Ocorre, no entanto, que, considerando a colonialidade - do poder, do saber e também das definições de humanidade -, é preciso conduzir tais pesquisas dentro do marco dos estudos decoloniais, mesmo para perceber, como já disse, que inclusive nossas noções sobre sexo e gênero estão informadas pelas noções de raça, e que estas, em conjunto, assentam-se no que chamei de dicotomia fundante da colonialidade: aquela que opõe humanos e não humanos. Isso significará que essa leitura performativa para uma hermenêutica jurídica antiessencialista e decolonial dos direitos fundamentais fundados na dignidade da pessoa humana deve ser uma leitura decolonial, que inclui, portanto, examinar como a colonialidade define não só o poder e o saber, mas as nossas formas de definição do humano (QUIJANO, 1991). Essa leitura, assim, afeta também a nossa forma de fazer uma hermenêutica feminista, uma vez que exigirá descolonizar os referenciais e as ideias sobre feminismo, gênero e mesmo sobre mulheres, uma vez que demanda que se tenha como categoria central, ao lado dessas, aquela da raça.

\section{Consideraçōes finais}

Falar em Constituição, em direitos fundamentais e em sua interpretação é tocar, de algum modo, no embate universalismo/individualismo, a exemplo da oposição eu e nós de Angela Harris. No constitucionalismo democrático, esse embate ganha representações como o embate entre democracia e direitos fundamentais, poder constituído e poder constituinte, entre autonomia privada e autonomia pública. A existência dele não é problema, estar na fronteira é o que defendo: não há no constitucionalismo consenso possível, mas o exercício de um dissenso expansivo. Abrir espaço para o dissenso e estimular as instituições em que ele pode se manifestar é fundamental (MOUFFE, 2000, p. 17) para o exercício democrático e para a hermenêutica de direitos fundamentais.

Quando se lê o direito como performatividade, entende-se que não há consenso na construção do direito, que a indecidibilidade (DERRIDA, 2010, p. 47) é sua característica fundamental, e, se assim é, a interpretação da Constituição - e especialmente dos direitos fundamentais - tem que tomar por base essa característica, além de, como define Peter Häberle (1997, p. 51), levar em conta que o direito constitucional é um direito de conflito e compromisso. É a admissão de que, em direito e política (e o direito constitucional é o local do exercício jurídico da política), não há consenso sobre o conteúdo do direito. Deve haver sempre o respeito ao e a abertura para o dissenso sobre o conteúdo (NEVES, 2012, p. 144), ${ }^{20}$ e essa abertura também pressupõe que a interpretação da Constituição tenha por autores todos aque- 
les envolvidos no jogo político, o que quer dizer que a interpretação não é uma atividade essencialmente estatal ou jurídica, pois "[...] quem vive a norma, acaba por interpretá-la, ou pelo menos por co-interpretá-la" (HÄBERLE, 1997, p. 13). ${ }^{21}$ Do mesmo modo, não há nem é possível haver consenso sobre o que constitui pessoa humana, povo ou homens e mulheres, e nem há consenso sobre que direitos são necessários para a garantia da dignidade - especialmente considerando que esses direitos são, na sua história, instituídos a partir do binário masculino/feminino no marco da raça.

Ainda que este artigo não tenha trabalhado a ideia de Häberle de uma sociedade aberta de intérpretes da Constituição como método de interpretação - por não ser esse o objetivo do trabalho -, a ideia importa nesse esboço final para pensar que mesmo dar sentido ao direito, compreender seus significados, compreender o significado dos termos que utiliza para definir seus "destinatários" precisa levar considerar justamente quem são esses. E, em termos de corporeidades, esses são muitos. Se quem vive a norma, interpreta, é preciso expandir os conceitos que falam sobre esse quem. São muitas vidas e vivências diversas que não podem se limitar ao uso do gênero como uma realidade natural ou como um modo de categorização biológica de sujeitos, ou uma sua decorrência ou sob um ideal europeu-branco. Mas, quem vive a norma? E como se vive a norma? E se a vivência desconfirma, desestabiliza, desloca a norma? Que norma? Para responder a essas perguntas, uma hermenêutica feminista antiessencialista organizada e realizada nos marcos de gênero e raça se move na consideração de ser o direito.
Assim, nesse marco hermenêutico, entendo que: (i) conhecemos os corpos por meio da linguagem; (ii) os corpos falantes falam mais do que a linguagem hegemônica sobre eles autoriza, a realidade, a materialidade, a vivência, a experiência dos corpos falantes sempre excedem a linguagem a seu respeito; (iii) os processos centrais de significação dos corpos têm por ferramentas, no contexto da colonialidade, sua sexualização/generificação e sua racialização; (iv) os processos de significação dos corpos, no marco da colonialidade, funcionam como instrumentos de preenchimento do binário humano/não humano; (v) raça, sexo e gênero são categorias que devem ser examinadas em conjunto, por se produzirem mutuamente; (vi) reconstruir a linguagem sobre os corpos para permitir mais se torna uma reivindicação na teoria.

O que significa, então, introduzir o corpo no direito para uma hermenêutica constitucional? Significa, primeiramente, perceber que a modernidade que o inspira ou esquece o corpo ou oferece apenas um corpo como referência. Mas, em sua operação mais central, essa modernidade como colonialidade não lê os corpos de maneira igual e usa linguagens de sexo, gênero e raça: o gênero é racializado, o ideal de gênero é construído na colonialidade, e ela não só produz um ideal de gênero em que não heteroconformes e não cissexuais são o abjeto, seu ideal é também branco e se faz construindo um "sujeito hipersexualizado", não humano, animalesco; segundamente, significa perceber que esse ideal serve a preencher a dicotomia de não humanos e humanos em que a colonialidade se funda e que, por consequência, 
é utilizada nas categorias do humano no direito: povo e dignidade da pessoa humana.

Depois que o corpo como múltiplas formas de performatividade é introduzido no direito, as categorias jurídicas que contêm o humano, em suas narrativas e teorias dominantes, revelam-se partes da linguagem da colonialidade. E é essa a tarefa que tem que ser realizada nos moldes de interpretação apresentados neste artigo, buscando desrecalcar e revelar o que escondeu a teoria jurídico-constitucional, em especial, nos marcos de gênero e raça ao falar do humano.

\section{Abstract}

In the attempt to using gender and race as categories of reading and interpretation of the Brazilian Constitution, in its 30 years of existence, this article brings, at first a discussion about legal language to establish it as performativity. Alongside this, it presents Law as part of coloniality. With these two theoretical bases, performativity and coloniality, it understands the Constitution as a performative text that creates realities and that, in order to be interpreted in an anti-essentialist and decolonial feminist way, must reveal and reinscribe its colonial heritage. The defense of a constitutional hermeneutic of gender and race, will then be written by thinking the body as a legal category, denaturalizing the understandings we have about it and taking it in its multiple forms and experiences to allow more in our readings about the human in Law and constitutionalism.

Keywords: Decoloniality. Feminism. Gender. Constitutional hermeneutics. Race.

\section{Resumen}

En el intento de utilizar género y raza como categorías de la lectura e interpretación de la Constitución brasileña, en estos 30 años de existencia, el presente artículo promueve, en primer lugar, una discusión sobre el lenguaje jurídico para asentarla como performatividad. Al lado de eso, presenta el Derecho como parte de la colonialidad. Con estas dos bases teóricas, la performatividad y la colonialidad, entiende la Constitución como texto performativo que crea realidades y que, para que pueda ser interpretada de modo feminista anti-esencialista y decolonial, necesita revelar y reinscribir esa su herencia colonial. La defensa de una hermenéutica constitucional de género y raza, así, pasará por pensar el cuerpo como categoría jurídica, desnaturalizando las comprensiones que tenemos a su respecto y tomándolo en sus múltiples formas y vivencias para permitir más en nuestras lecturas sobre lo humano en Derecho y en el constitucionalismo.

Palabras clave: Decolonialidad. Feminismo. Género. Hermenéutica constitucional. Raza.

\section{Notas}

1 O que chamo de hermenêutica feminista antiessencialista e decolonial é parte do que entendo por uma narrativa expansiva do humano no direito. $\mathrm{O}$ uso de expansivo foi desenvolvido em Têmis travesti - as relações entre gênero, raça e direito na busca de uma hermenêutica expansiva do "humano" no direito (MAGALHÃES GOMES, 2017c). Este artigo, então, é um extrato daquele trabalho, consolidando, contudo, de modo mais específico, apenas a exploração da questão hermenêutica. 
2 Inserir o gênero como categoria de análise do direito também significa um passo de ruptura com a racionalidade moderna da separação sujeito-objeto. Ao tomar a noção do gênero como performatividade, o fazer, o refazer e o desfazer os gêneros pelos sujeitos, em suas experiências, mostrarão ainda mais a artificialidade dessa separação. Ao tomar o corpo na teoria, como fonte de teoria, ele deixa de ser o objeto de estudo do direito e é, ao mesmo tempo, sujeito e objeto. A respeito da racionalidade científica moderna, cf. Quijano (1991).

3 Para fazer as leituras indicadas na introdução, devo fazer outro destaque: leio as relações entre gênero, raça e direito dentro das teorias da performatividade e da decolonialidade. Tratarei um pouco dessas teorias também neste texto, mas, como faço essas relações de modo mais específico e evitando explicações longas neste espaço curto, remeto a leitora e o leitor aos textos: Gênero como categoria de análise decolonial (MAGALHÃES GOMES, 2018); O juiz (diante) da desconstrução: hermenêutica constitucional e fracasso à luz da filosofia de Jacques Derrida (MAGALHÃES GOMES, 2017b); Corpos falantes - a teoria do gênero como performatividade na perspectiva decolonial (MAGALHÃES GOMES, 2017a).

4 A esse respeito, entre outros, ver Excitable speech (BUTLER, 1997a) e Problemas de gênero (BUTLER, 2013).

5 A esse respeito, ver, entre outros, La temporalidad como política: nación, formas de pasado y perspectivas poscoloniales (RUFER, 2010); Colonialidade do poder, eurocentrismo e América Latina (QUIJANO, 2005); Pensamento descolonial e teoria crítica dos direitos humanos na América Latina: um diálogo a partir da obra de Joaquín Herrera Flores (CASTILHO, 2013).

6 Pensar a colonialidade significa, entre outras coisas, identificar que, junto com a colonização das Américas, cria-se a raça como uma categoria que sustenta nossas formas de organizar o poder e o saber, como uma norma de formação e relação dos sujeitos (QUIJANO, 2005). Essa racialização que cria um outro excluído e, a partir do qual se constitui a modernidade colonial, é a cola que sustenta o que Butler chamou de evocação de ações prévias que acumulam autoridade, que sustentam a cadeia histórica de sentidos de um performativo, como falarei adiante, mas que ela não identificou como sendo a colonialidade.

7 Sobre linguagem de criação e manutenção de violências, refiro-me ao texto de Walter Benjamin, Para a crítica da violência (2013), e à posterior análise deste por Jacques Derrida (2010).
8 No contexto situacional em que é produzido, considerado no plano do conteúdo e da expressão, o texto jurídico é, além das palavras que o compõem e das idéias que exprime, ação manifestada pelo verbo. Nesse sentido, se compreende a afirmação de Greimas (1976, p. 88): “A enunciação inicial: 'O Presidente da República promulga a lei cujo teor é o seguinte' não é somente a expressão de um querer coletivo delegado: enquanto enunciação, ela instaura à maneira do fiat divino o conjunto de enunciados jurídicos que somente existirão em virtude deste ato performador inicial" (MACIEL, 2008, p. 4).

9 "Segundo Derrida (1990), a pensée de Pascal alcança a mais intrínseca estrutura, normalmente negligenciada pela crítica da ideologia jurídica, qual seja, a força performativa que é sempre uma força interpretativa e que está lá, no momento de fundação e justificação do direito. Neste momento (do ato fundador), o direito mantém uma complexa relação interna com a força (o poder ou a violência) e a justiça (no sentido de ou como direito), igualmente, vai experimentá-la; isto é, da operação que consiste em fundar, inaugurar, justificar e fazer o direito, um golpe de força, uma violência performativa e, assim, interpretativa, que em si mesma não é justa nem injusta e que justiça ou lei anterior alguma poderia garantir, contestar ou invalidar" (CHUEIRI, 2011, p. 804).

10 Para Anna Maria Becker Maciel, “[...] são performativos os enunciados legislativos que decretam, promulgam, definem, criam, nomeiam, demitem, exoneram, autorizam, proíbem ou permitem, bem como os enunciados judiciais que absolvem, condenam ou dão quitação [...]. Tais enunciados, centrados em verbos performativos, quando emitidos nas condições legais previstas, são a causa do surgimento de fatos. Na realidade, tais verbos determinam mudanças no espaço jurídico, seja porque criam ou anulam entidades, ou porque alteram as relações entre pessoas, ou até alteram as próprias pessoas, conferindo-lhes poderes, diretos ou obrigações que não possuíam" (2001, p. 115).

11 Algumas das referências de destaque do feminismo negro e a crítica que suas autoras e ou militantes fazem às universalizações cegas à raça produzidas pelo feminismo branco e europeu estão, entre outras, em Angela Davis (2016), Bell Hooks (1981, 1995, 2000), Lélia Gonzales (1984), Luiza Bairros (1995), Patricia Hill Collins (2000) e Sueli Carneiro $(2003,2011)$.

12 Do feminismo decolonial, cito, entre outras, $\mathrm{Yu}$ derkys Espinosa-Miñoso (2014), Maria Lugones (2014), Breny Mendoza (2010) e Rira Segato (2012, 2013a). 
13 É também possível pensar a obra de Katherine Bartlet como uma possibilidade de realização de hermenêutica jurídica feminista antiessencialista. Assim como Angela Harris, a autora critica produções clássicas do feminismo jurídico, em especial aquela produzida por Catherine MacKinnon. Utilizo-me, contudo, da obra de Angela Harris de modo mais específico por falar em leitura constitucional e pelo fato de que esta autora trata a raça como categoria central da sua escrita, enquanto em Bartlet ela aparece de modo tangencial. Sobre essa crítica ao pensamento de Mackinnon, ver Race and essentialism in feminist legal theory (HARRIS, 1990) e MacKinnon's feminism: power on whose terms (BARTLET, 1987).

14 A respeito das construções da modernidade sobre o sujeito e o ser, especialmente em termos de raça, conferir a obra de Gislene Aparecida dos Santos (2002): A invenção do ser negro: um percurso das ideias que naturalizaram a inferioridade dos negros.

15 Em uma das suas composições, LGBTTQIA corresponde a lésbicas, gays, bissexuais, travestis, transexuais, queer, intersexuais e assexuais e agêneros.

16 A esse respeito, ver, entre outras, Angela Davis (2016) e Lélia Gonzales (1984).

17 Por isso, Bourdieu destaca: “O direito é, sem dúvida, a forma por excelência do poder simbólico de nomeação que cria as coisas nomeadas e, em particular, os grupos; ele confere a estas realidades surgidas das suas operações de classificação toda a permanência, a das coisas, que uma instituição histórica é capaz de conferir a instituições históricas. Ainda, o direito é a forma por excelência do discurso atuante, capaz, por sua própria força, de produzir efeitos. Não é demais dizer que ele faz o mundo social, mas com a condição de se não esquecer que ele é feito por este. Cabe ressaltar que tais operações se desenvolvem no âmbito de estruturas estruturadas, historicamente construídas, que possuem o fito de 'construir o mundo', mas dentro dos limites da sua correspondência com estruturas preexistentes" (2011, p. 233-238).

18 Uma crítica a essa abordagem seria que a mesma avaliação poderia - ou deveria - ser realizada com todas as demais Constituições brasileiras. Ocorre, no entanto, que o atual documento constitucional representa - também histórica e politicamente - um momento juridicamente relevante, ao dar especial destaque à consagração dos direitos fundamentais, seja pelo conhecido e extenso rol de direitos assegurados, seja pela inovação da posição desses direitos no texto constitucional, diferente do exemplo das Constituições anteriores, mais preocupadas em desenhar os poderes e sua organização do que estabelecer que direitos tem esse "povo" em nome do qual alegam falar: as Constituições anteriores tratavam dos direitos fundamentais a partir dos seus artigos 70/100. A organização tópica e lógica mostra que, antes de pensar em estabelecer os direitos daqueles de onde "emana o poder", estrutura-se esse poder. A condição de possibilidade do exercício do poder parece ser a sua organização e a disciplina do seu modo de fazer, e não a existência de um corpo de direitos que garanta que o povo possa exercer, viver e discutir a legitimidade de seus representantes. Sobre essa restruturação textual, conferir o trabalho de Hermes Zaneti Jr. (2007). O caso da Constituição de 1988, portanto, merece análise individual - seja pelo motivo óbvio de ser o texto vigente, seja pela circunstância de ter os direitos fundamentais como fundamento do Estado democrático de direito que institui. Ademais, fala o referido texto em "homens e mulheres [...] iguais em direitos e obrigações" (BRASIL, 1988), não tendo se limitado a usar apenas os termos "povo" ou "todos", diferente do que se observa nos textos anteriores. A Constituição de 1824 (BRASIL, 1824) não trata de "povo", mas de "nação", em seu artigo $1^{\circ}$. Não fala de direitos fundamentais, apenas define a cidadania no artigo $6^{\circ}$. A Constituição da República de 1891 (BRASIL, 1891) continua falando em "nação", em seu artigo $1^{\circ}$, seguindo a tendência do século, mas fala em "representantes do povo brasileiro". Sua "Declaração de Direitos" está listada na Seção II, a partir do artigo 72, usando a expressão "Todos são iguaes perante a lei", em seu parágrafo $2^{\circ}$. O texto de 1934 (BRASIL, 1934) segue a mesma linha, falando em "nação" e "povo", e traz sua "Declaração de Direitos" no Título III, a partir do artigo 106. No artigo 113, 1, fala de igualdade e da não discriminação por sexo: "1) Todos são iguais perante a lei. Não haverá privilégios, nem distinções, por motivo de nascimento, sexo, raça, profissões próprias ou dos pais, classe social, riqueza, crenças religiosas ou idéias políticas" (BRASIL, 1934). Em 1937 ¿ o texto não só fala "em nome do povo", mas alega atender às "legitimas aspirações do povo brasileiro à paz política e social, profundamente perturbada por conhecidos fatores de desordem" (BRASIL, 1937), retrato do estado ditatorial que atravessava o país. Usa pela primeira vez a expressão "Dos Direitos e Garantias Individuais", que vêm listados a partir do artigo 122. O mesmo se vê na Constituição de 1946 (BRASIL, 1946), a partir do artigo 141. O 
texto de 1967 (BRASIL, 1967a), com emenda de 1969 (BRASIL, 1967b), segue esse modelo, a partir do seu artigo 153. Não fosse tudo isso motivo suficiente, o texto em questão faz referência à dignidade da pessoa humana como fundamento da República, ponto essencial para o desenvolvimento da tese proposta neste texto.

19 Ao examinar a obra de Mauricio Villegas, Rita Segato comenta que este, em "[...] análisis exhaustivo de los aspectos performáticos, ilocucionarios y productores de realidad de todo discurso, y luego de hacer notar el carácter discursivo de toda legislación, García Villegas concluye que, como todo discurso, la ley tiene el poder simbólico de dar forma a la realidad social, un poder que reside en su legitimidad para dar nombres" (2013a, p. 124-125). Segato, no entanto, comenta que seria necessário dizer mais sobre o direito e virar os olhos dessa análise sobre seus efeitos e forças discursivas para um possível papel de agitação que o uso do direito possa vir a ter nas mãos de grupos minorizados (SEGATO, 2013b, p. 124125). O texto de Segato vem, no entanto, antes de uma segunda edição da obra de Villegas, em que ele realiza exatamente essa inversão de visão. Diz ele: "Estas eran, y siguen siendo, las ideas centrales de este libro. Sin embargo, los énfasis y los desarrollos surgidos a partir de esas ideas han cambiado en esta segunda edición. La dimensión dominadora de la eficacia simbólica sigue estando presente, pero ahora se complementa con la dimensión emancipadora de los textos jurídicos, que, si bien estaba latente en la teoría inicial no tenía la importancia que tiene ahora. El derecho no está destinado a servir inevitablemente como instrumento de dominación política" (VILLEGAS, 2014, p. 4). É nessa onda que este trabalho se insere, nessa procura de um poder de agitação e expansão no uso do direito.

20 Marcelo Neves fala em dissenso sobre o conteúdo e consenso sobre o procedimento. Há mais, contudo: se procedimento também é garantia e é o meio pelo qual as vozes dissonantes a respeito das exclusões promovidas no conteúdo chegam ao cenário político, então também esse deve estar aberto à discussão. $O$ procedimento só pode ser dado por legítimo na medida em que permite que seja introduzido o dissenso. Se assim não permite, deverá ser objeto de modificação.

21 Como comenta Ralph Christensen na introdução ao livro de Friedrich Muller: “O problema central aqui é o fato de que o povo enquanto destinatário de prestações civilizatórias do estado deve poder ser genericamente posto em condições de perceber e defender a tarefa de preservação de uma constituição democrática por meio da sua instituição permanentemente renovada. Entra assim no campo visual, partindo das margens da modernidade periférica, mas como fenômeno crescentemente típico para o centro da sociedade, também para as nossas assim chamadas sociedades desenvolvidas, o problema da exclusão de grupos populacionais inteiros de todos os sistemas funcionais da sociedade" (2013, p. 41).

\section{Referências}

ATHANASIOU, Athena; BUTLER, Judith. Dispossession - the performative in the political. Cambridge: Polity, 2013.

AUSTIN, John L. How to do things with words. 2. ed. Harvard: Harvard University Press, 1975.

BAIRROS, Luiza. Nossos feminismos revisitados. Revista de Estudos Feministas, Florianópolis, ano 3, n. 2, p. 458-463, 1995.

BARTLET, Katharine T. MacKinnon's feminism: power on whose terms. California Law Review, Berkeley, v. 75, n. 4, 1987. Disponível em: <http:/ /scholarship.law.berkeley.edu/californialawreview/vol75/iss4/7>. Acesso em: 12 jan. 2016.

BENJAMIN, Walter. Para a crítica da violência. In:__. Escritos sobre mito e linguagem. 2. ed. Trad. Susana Kampf. São Paulo: Duas Cidades, 2013. p. 121-156.

BOURDIEU, Pierre. O poder simbólico. Trad. Fernando Tomaz. 15. ed. Rio de Janeiro: Bertrand Brasil, 2011.

BRASIL. Constituição da República dos Estados Unidos do Brasil (de 24 de fevereiro de 1891). Rio de Janeiro, 1891. Disponível em: <http:// www.planalto.gov.br/ccivil_03/Constituicao/Constituicao91.htm>. Acesso em: 15 maio 2018.

Constituição da República dos Estados Unidos do Brasil (de 16 de julho de 1934). Rio de Janeiro, 1934. Disponível em: <http:// www.planalto.gov.br/ccivil_03/Constitui- 
cao/Constituicao34.htm>. Acesso em: 15 maio 2018.

Constituição da República Federativa do Brasil de 1967. Brasília, DF, 1967a. Disponível em: <http://www.planalto.gov.br/ ccivil_03/Constituicao/Constituicao67.htm>. Acesso em: 15 maio 2018.

. Constituição da República Federativa do Brasil de 1967. (Redação dada pela Emenda Constitucional $\mathrm{n}^{\circ} 1$, de 17.10.1969). Brasília, DF, 1967b. Disponível em: <http://www.planalto.gov.br/ccivil_03/Constituicao/Constituicao67EMC69.htm>. Acesso em: 15 maio 2018.

Constituição da República Federativa do Brasil de 1988. Brasília, DF, 1988. Disponível em: <http://www.planalto.gov.br/ccivil_03/constituicao/constituicao.htm>. Acesso em: 15 maio 2018.

Constituição dos Estados Unidos do Brasil (de 10 de novembro de 1937). Rio de Janeiro, 1937. Disponível em: <http:/ / www.planalto.gov.br/ccivil_03/Constituicao/Constituicao37.htm>. Acesso em: 15 maio 2018.

Constituição dos Estados Unidos do Brasil (de 18 de setembro de 1946). Rio de Janeiro, 1946. Disponível em: <http://www.planalto.gov.br/ccivil_03/Constituicao/Constituicao46.htm>. Acesso em: 15 maio 2018.

Constituição Politica do Imperio do Brazil (de 25 de março de 1824). Rio de Janeiro, 1824. Disponível em: <http://www.planalto. gov.br/ccivil_03/Constituicao/Constituicao24.htm>. Acesso em: 15 maio 2018.

BUTLER, Judith. Excitable speech: a politics of the performative. New York: Routledge, 1997a.

Problemas de gênero: feminismo e subversão da identidade. Trad. Renato Aguiar. Rio de Janeiro: Civilização Brasileira, 2013.

The psychic life of power: theories in subjection. Stanford: Stanford University Press, $1997 b$.
When gesture becomes event. Theater Performance Philosophy - International Conference, 2014. Disponível em: <https://www. youtube.com/watch? $v=$ iuAMRxSH--s>. Acesso em: 20 abr. 2016.

CARNEIRO, Aparecida Sueli. Enegrecer o feminismo: a situação da mulher negra na américa latina a partir de uma perspectiva de gênero. 2011. Disponível em: <http://www.geledes. org.br/enegrecer-o-feminismo-situacao-da-mulher-negra-na-america-latina-partir-de-uma-perspectiva-de-genero/\#gs.YETrpfQ>. Acesso em: 20 ago. 2013.

. Mulheres em movimento. Revista Estudos Avançados, São Paulo, v. 17, n. 49, p. 117-132, set./dez. 2003.

CASTILHO, Natalia Martinuzzi. Pensamento descolonial e teoria crítica dos direitos humanos na América Latina: um diálogo a partir da obra de Joaquín Herrera Flores. Dissertação (Mestrado em Direito) - Programa de Pós-Graduação em Direito, Universidade do Vale do Rio dos Sinos, Florianópolis, 2013.

CHUEIRI, Vera Karam de. Agamben e Derrida: a escrita da lei (sem forma). Pensar, Fortaleza, v. 16, n. 2, p. 795-824, jul./dez. 2011.

COLLINS, Patricia Hill. Black feminist thought. New York: Routledge, 2000.

DAVIS, Angela. Mulheres, raça e classe. Trad. Heci Regina Candiani. São Paulo: Boitempo, 2016.

DERRIDA, Jacques. Assinatura acontecimento contexto (1972). In: . Margens da Filosofia. Trad. Joaquim Torres Costa e António M. Magalhães. Campinas: Papirus, 1991. p. 15-51. Before the Law. Ed. Derek Attridge. New York: Routledge, 1992.

Força de lei: o fundamento místico da autoridade. Trad. Leyla Perrone Moyses. São Paulo: WMF Martins Fontes, 2010.

ESPINOSA-MIÑOSO, Yuderkys. Una crítica descolonial a la epistemología feminista. El Co- 
tidiano, Distrito Federal, México, n. 184, p. 7-12, marzo/abr. 2014.

FAUSTO-STERLING, Anne. Sex/gender: biology in a social world. New York: Routledge, 2012.

FELMAN, Shoshana. The scandal of the speaking body: Don Juan with J. L. Austin, or seduction in two Languages. Stanford: Stanford University Press, 2003.

GONZALES, Lélia. Racismo e sexismo na cultura brasileira. Revista Ciências Sociais Hoje, Brasília, DF, p. 223-244, 1984.

GOULD, Timothy. The unhappy performative. In: PARKER, Andrew; SEDGWICK, Eve Kosovsky (Ed.). Performativity and performance. New York: Routledge, 1995. p. 19-44.

HÄBERLE, Peter. Hermenêutica constitucional: a sociedade aberta dos interpretes da Constituição: contribuição para a interpretação pluralista e "procedimental" da Constituição. Trad. Gilmar Ferreira Mendes. Porto Alegre: Sergio Antonio Fabris, 1997.

HARRIS, Angela P. Race and essentialism in feminist legal theory. Stanford Law Review, v. 42, n. 3, p. 581-616, 1990. Disponível em: <http:/ / works.bepress.com/angela_harris/6>. Acesso em: 20 ago. 2013.

HOOKS, Bell. Ain't I a woman. London: Pluto Press, 1981.

. Feminism is for everybody. Cambridge: South End Press, 2000.

Intelectuais negras. Revista de Estudos Feministas, Florianópolis, ano 3, n. 2, p. 463-478, 1995.

LUGONES. Maria. Rumo a um feminismo decolonial. Estudos Feministas, Florianópolis, v. 22, n. 3, p. 935-952, set./dez. 2014.

MACIEL, Anna Maria Becker. O verbo performativo na linguagem legal. In: ENCONTRO DO CÍRCULO DE ESTUDOS LINGUÍSTICOS DO SUL, 8, 2008, Porto Alegre, RS. Anais... Pelotas, 2008. p. 1-10. Disponível em <http://
www.celsul.org.br/Encontros/08/Herbert_ Welker.pdf>. Acesso em: 20 jun. 2016.

Para o reconhecimento da especificidade do termo jurídico. Tese (Doutorado em Letras) - Programa de Pós-Graduação em Letras, Universidade Federal do Rio Grande do Sul, Porto Alegre, 2001.

MAGALHÃES GOMES, Camilla de. Corpos falantes - a teoria do gênero como performatividade na perspectiva decolonial. In: XIII Mundo de mulheres e fazendo gênero XI. Florianópolis: UFSC, 2017a. p. 1-13. Disponível em <http://www.wwc2017.eventos.dype. com.br/resources/anais/1518796654_ARQUIVO_ST009-CorposFalantes-CamillaMagalhaesGomes.pdf>. Acesso em 13 maio 2018.

Gênero como categoria de análise decolonial. Civitas, Porto Alegre, v. 18, n. 1, p. 6582, jan./abr. 2018.

O juiz (diante) da desconstrução. Revista de Estudos Constitucionais, Hermenêutica e Teoria do Direito, São Leopoldo, v. 9, n. 2, p. 125-135, maio/ago. 2017b.

Têmis travesti - as relações entre gênero, raça e direito na busca de uma hermenêutica expansiva do "humano" no direito. 2017. 236 f. Tese (Doutorado em Direito) - Programa de Pós-Graduação em Direito, Universidade de Brasília, Brasília, 2017c.

MALDONADO-TORRES, Nelson. A topologia do ser e a geopolítica do conhecimento. Modernidade, império e colonialidade. Trad. Inês Martins Ferreira. Revista Crítica de Ciências Sociais, Coimbra, v. 80, p. 71-114, mar. 2008.

. Sobre la colonialidad del ser: contribuciones al desarrollo de un concepto". In: CASTRO-GOMEZ, Santiago; GROSFOGUEL, Ramón (Ed.). El giro decolonial: reflexiones para una diversidad epistémica más allá del capitalismo global. Bogotá: Iesco-Pensar-Siglo del Hombre Editores, 2007. p. 127-167.

MBEMBE, Achille. Necropolitics. Public Culture, Durham, v. 15, p. 11-40, 2003. 
MENDOZA, Breny. La epistemología del sur, la colonialidad del género y el feminismo latino-americano. In: MINOSO, Yuderkys Espinosa (Coord.). Aproximaciones críticas a las prácticas teórico-políticas del feminismo latinoamericano. Buenos Aires: En la Frontera, 2010. p. 19-36.

MIGNOLO, Walter D. Local histories/global designs: coloniality, subaltern knowledges, and border thinking. Princeton, NJ: Princeton University Press, 2000.

MOUFFE, Chantal. Deliberative democracy or agonistic pluralism. Viena: Institut für Höhere Studien (IHS), 2000. Disponível em: <http:/ / www.ihs.ac.at/publications/pol/pw_72. pdf>. Acesso em: 4 jan. 2013.

MULLER, Friedrich. Quem é o povo?: a questão fundamental da democracia. Trad. Peter Naumann. 7. ed. São Paulo: Revista dos Tribunais, 2013.

NEVES, Marcelo. Entre Têmis e Leviatã: uma relação difícil. 3. ed. São Paulo: WMF Martins Fontes, 2012.

NIGRO, Rachel. A virada linguístico-pragmática e o pós-positivismo. Direito, Estado e Sociedade, Rio de Janeiro, n. 34, p. 170-211, jan./jun. 2009.

QUIJANO, A. Colonialidade do poder, eurocentrismo e América Latina. In: LANDER, Edgardo (Org.). A colonialidade do saber: eurocentrismo e ciências sociais. Perspectivas latino-americanas. Buenos Aires: CLACSO, 2005. p. 117-142. Disponível em: <http:// biblioteca. clacso.edu.ar/clacso/sur-sur/20100624103322 /12_Quijano.pdf>. Acesso em: 02 maio 2016.

La modernidad, el capital y América Latina nacen el mismo día, entrevista dada a Nora Velarde. ILLA - Revista del Centro de Educación y Cultura, Lima, n. 10, p. 42-57, enero 1991.
RUFER, Mario. La temporalidad como política: nación, formas de pasado y perspectivas poscoloniales. Memoria y Sociedad, Bogotá, v. 14, n. 28, p. 11-31, enero/jun. 2010.

SANTOS, Gislene Aparecida dos. A invenção do ser negro: um percurso das ideias que naturalizaram a inferioridade dos negros. São Paulo: Educ/Fapesp; Rio de Janeiro: Pallas, 2002.

SCOTT, Joan W. Gender: a useful category of historical analysis. American Historical Review, Washington, v. 91, p. 1053-1075, 1986.

SEGATO, Rita Laura. Gênero e colonialidade: em busca de chaves de leitura e de um vocabulário estratégico descolonial. E-cadernos CES, Coimbra, v. 18, p. 1-5, 2012.

Género, política e hibridismo en la transnacionalización de la cultura yoruba. In: . Las estructuras elementales de la violencia. 2. ed. Buenos Aires: Prometeo, 2013a. p. 221-248. . Las estructuras elementales de la violencia. 2. ed. Buenos Aires: Prometeo, 2013b.

VILLEGAS, Mauricio. La eficacia simbólica del derecho: ideas para una sociología política del campo jurídico en América Latina. Bogotá: Instituto de Estudios Políticos y Relaciones Internacionales, Universidad Nacional de Colombia, 2014.

VIVEIROS DE CASTRO, Eduardo. Metafísicas canibais: elementos para uma antropologia pós-estrutural. São Paulo: Cosac Naify, 2015.

WARAT, Luis Albert. O direito e a sua linguagem. Porto Alegre: Sergio Antonio Fabris, 1995.

ZANETI JR., Hermes. Processo constitucional - o modelo constitucional do processo civil brasileiro. Rio de Janeiro: Lumen Juris, 2007. 